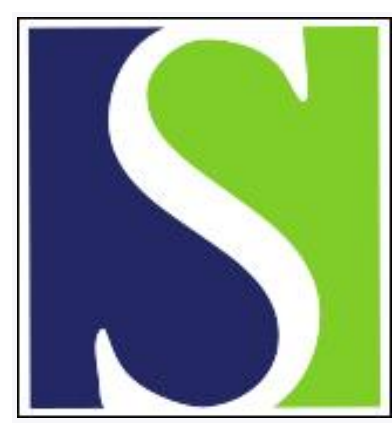

Scand J Work Environ Health 1989;15(2):130-135

https://doi.org/10.5271/sjweh.1872

Issue date: Apr 1989

Regional cerebral blood flow at the time of diagnosis of chronic toxic encephalopathy induced by organic-solvent exposure and after the cessation of exposure.

by Hagstadius S, Orbaek P, Risberg J, Lindgren M

Affiliation: Department of Psychiatry I, University Hospital, Lund, Sweden.

This article in PubMed: www.ncbi.nlm.nih.gov/pubmed/2772575

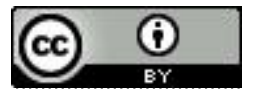




\title{
Regional cerebral blood flow at the time of diagnosis of chronic toxic encephalopathy induced by organic-solvent exposure and after the cessation of exposure
}

\author{
by Stefan Hagstadius, BA, ${ }^{1}$ Palle $\emptyset$ rbæk, MD, ${ }^{2}$ Jarl Risberg, $\mathrm{PhD},{ }^{1}$ May Lindgren, BA ${ }^{1}$ \\ HAGSTADIUS S, ØRBÆK P, RISBERG J, LINDGREN M. Regional cerebral blood flow at the time \\ of diagnosis of chronic toxic encephalopathy induced by organic-solvent exposure and after the cessation \\ of exposure. Scand J Work Environ Health 1989;15:130-5. Regional cerebral blood flow was measured \\ in patients with the diagnosis of chronic toxic encephalopathy induced by exposure to organic solvents. \\ Measurements were made at the time of diagnosis and 24-84 months after the cessation of exposure. \\ During the follow-up the patients were carefully examined for other possible causes of brain dysfunction. \\ Comparisons were made to unexposed and solvent-exposed referents. At the first examination the pa- \\ tients had a $7 \%$ lower mean flow level than the unexposed referents and a $5 \%$ lower level than the ex- \\ posed workers. The largest flow differences were seen in the frontotemporal areas. At the follow-up, the \\ difference in the mean flow level between the patients and referents was no longer significant. Regionally, \\ the flow had increased, especially in areas which initially showed the most pronounced decreases. There \\ was a significant negative correlation between the initial cerebral blood flow level and the degree of nor- \\ malization of the flow level at follow-up.
}

Key terms: brain dysfunction, cerebral circulation, exposure discontinuation, psychoorganic syndrome, toxic solvents.

Several studies have provided evidence of chronic effects of long-term exposure to organic solvents on the central nervous system. Exposed subjects have been shown to display memory disturbances, tiredness, irritability, emotional lability, difficulties to concentrate, and loss of initiative, a cluster of symptoms referred to as the psychoorganic or neurasthenic syndrome $(1-4)$. Neuropsychological investigations on exposed workers have shown subnormal scores on tests measuring memory functions, visual perceptual abilities, and psychomotor functions $(2,5-8)$. This type of brain dysfunction, named chronic toxic encephalopathy, has been recognized as a diagnostic entity for more than a decade in the Scandinavian countries.

In the further study of brain dysfunction associated with solvent exposure, objective methods for evaluating central nervous system function are valuable complements to clinical and neuropsychological techniques. Measurements of the regional cerebral blood flow (regional CBF) by the ${ }^{133}$ Xenon inhalation method $(9,10)$ have revealed subnormal cerebral blood flow levels and specific patterns of regional flow pathology in patients with brain disorders such as organic dementia. For example, the method has proved to be highly discriminative between Alzheimer's and Pick's diseases and multiinfarct dementia (11).

\footnotetext{
1 Department of Psychiatry 1, University Hospital, Lund, Sweden.

2 Department of Occupational Medicine, Malmö General Hospital, Malmö, Sweden.
}

Reprint requests to: Mr S Hagstadius, Department of Psychiatry, University Hospital, S-221 85 Lund, Sweden.
The influence of alcohol on brain blood flow has also been studied. Chronic alcoholics have been found to have reduced regional CBF, especially in the frontal lobes (12). Some normalization has been seen after a period of abstinence (13). Patients with alcohol dementia have, however, a persistent regional $\mathrm{CBF}$ reduction (12). Thus specific patterns of regional CBF abnormalities have been demonstrated in patient groups with clinical symptoms somewhat similar to those observed in chronic toxic encephalopathy.

House painters with suspected chronic toxic encephalopathy and computerized tomographic findings indicating brain atrophy have been shown to have a $19 \%$ lower CBF level than referents (14). In a study of 32 exposed workers, Maximilian et al (15) found a $6 \%$ decrease in the mean flow level in comparison to estimated control values. We have previously reported a reduction of the CBF level in 50 exposed paint factory workers as compared to unexposed referents matched for age and education (16). Regionally, the exposed workers showed the largest decreases in the frontotemporal areas. The difference in flow level between the groups increased at higher accumulated exposure levels.

In the present study patients with clinically and neuropsychologically set diagnoses of chronic toxic encephalopathy were investigated with measurements of the regional $\mathrm{CBF}$ at the time of diagnosis and after 24-84 months without exposure. The objectives of the study were to confirm clinical and neuropsychological indications of brain dysfunction and to determine whether brain function had normalized after the cessation of exposure. 


\section{Subjects and methods}

Twenty-eight men with the diagnosis of chronic toxic encephalopathy induced by solvent exposure were examined. The diagnosis (17) was based on clinical evidence of neurasthenic symptoms and subnormal performance in the neuropsychological testing, preceded by extensive exposure to organic solvents [range 7-50 (median 26) years]. According to criteria of the World Health Organization (18), the patients all had mild toxic encephalopathy. The regional CBF results were used in the diagnostic evaluation only to exclude patients with other organic brain disorders causing neurasthenic symptoms. The patients were 33-63 (mean 50, SD 10) years of age at the time of the first examination. The clinical and psychometric findings have been described elsewhere (17).

The reference group consisted of 72 male volunteers from the same socioeconomic level as the study group. They were without occupational exposure to organic solvents and were selected on the basis of strict criteria for good health and the results of physical and neurological examinations and an evaluation of drinking and smoking habits. The referents were $28-68$ (mean 48, SD 12) years old.

Patients or referents with a history of severe head trauma, cerebrovascular disease, other neurological disorders, diffuse arteriosclerotic signs, alcohol/drug abuse, and psychiatric or somatic disease were excluded from the study.

Comparisons were also made with a group of 50 male paint factory workers exposed to mixtures of organic solvents (16). The age range of this group was 26-62 (mean 41, SD 10) years, and they had been exposed to solvents for at least 10 (mean 18, SD 10) years.

After the diagnosis of solvent-induced chronic toxic encephalopathy was established, the patients were granted compensation for occupational disease and were withdrawn from exposure. They have been clinically and neuropsychologically reexamined, and before inclusion in the present study they were subjected to a renewed careful differential diagnostic penetration to exclude other possible causes of brain dysfunction than solvent exposure (17). They were also investigated by computerized tomography (CT), which showed no deviations in brain morphology from healthy referents (19).

The patients had been exposed daily to solvents for $7-50$ (median 26) years at the time of the first clinical assessment. An exposure index was calculated from the multiplication of the years of exposure with an intensity factor (20), yielding an exposure index for the group in the range 12-100 (mean 48, SD 23). Eighteen of the patients were still exposed at the time of the initial regional CBF examination [mean age 48 (SD 11) years, exposure index 50 (SD 20)], while the remaining 10 patients had already been removed from ex- posure [mean age 52 (SD 9) years, exposure index 45 (SD 28)].

The noninvasive ${ }^{133}$ Xenon inhalation method was used for measuring regional CBF (10). The technique was outlined by Mallet \& Veall (21) and further developed by Obrist et al (22) and Risberg et al (9). A mixture of ${ }^{133}$ Xenon and air $(70-100 \mathrm{MBq} / \mathrm{l})$ is inhaled by the subject during $1 \mathrm{~min}$ via a face mask and a rebreathing spirometer system. This procedure is followed by $10 \mathrm{~min}$ of normal air breathing. The inert gamma-emitting tracer diffuses into brain tissue from arterial blood and is cleared by venous blood. The gamma radiation emitted by the tracer is continuously monitored by external scintillation detectors. The rate of washout of the tracer forms the basis for flow calculations according to principles described by Obrist et al (22) and Risberg et al (9). In our system (NOVO Diagnostic Systems Inhalation Cerebrograph), 32 detectors covered 16 homologous regions of each hemisphere. The detectors were placed in parallel at a right angle to each lateral surface of the head. The results presented are based on the initial slope index (ISI), which is an index dominated by the blood flow through grey matter (9).

The partial pressure of carbon dioxide in arterial blood $\left(\mathrm{apCO} \mathrm{CO}_{2}\right.$ ) was estimated from recordings of endtidal carbon dioxide concentrations (Beckman LB2 analyzer). Correction of flow values for variations in $\mathrm{apCO}_{2}$ was performed with the use of correction factors described by Maximilian et al (23).

\section{Design}

The regional $\mathrm{CBF}$ was measured with the subject resting supine on a comfortable bed. The subject's eyes were closed, and he was asked to relax without falling asleep. The measurement was preceded by some time of adjustment to the measurement situation. The subject's eyes were covered with eye pads, and ambient noise was kept at a minimum. Resting measurements were made at the time of diagnosis and 24-84 (mean $38.1)$ months after the cessation of exposure. All the subjects included in the study were examined under identical experimental conditions and with the same equipment.

\section{Data analysis}

Intragroup comparisons were made with paired-samples t-tests, and intergroup comparisons were done with two-sample t-tests. Pearson correlation coefficients were used for the investigation of covariation between the flow variables and exposure-free time, age, psychometric performance, and exposure index.

\section{Results}

\section{Mean cerebral blood flow}

Table 1 shows the mean right and left hemisphere CBF values of the patients at the initial measurement and 
at the follow-up in comparison with those of the reference group. Initially, the patients had a significantly lower mean flow. At the follow-up, the flow difference had diminished and was not statistically significant. Thus some normalization of the mean flow level was seen, but the flow increase did not reach statistical significance. Compared to the group of exposed workers, the patient group had a somewhat lower mean flow in both hemispheres on both measurement occasions.

\section{Regional cerebral blood flow}

Figure 1 shows regional flow differences between the patients and referents and the patients and the exposed workers at the initial regional CBF assessment. Compared to those of the referents, the regional flows were significantly lower in the patients at all detector sites except two (frontal-central) in the left hemisphere. The largest differences were seen in the prefrontal, frontotemporal, and inferior temporal areas bilaterally.

Table 1. Mean right and left hemisphere blood flow for the patients at the initial measurement (I) and at follow-up (II), and the corresponding values for the referents. Flow values were corrected for variations in the partial pressure of carbon dioxide in arterial blood $\left(\mathrm{apCO}_{2}\right)$ (two-sample t-test comparisons).

\begin{tabular}{|c|c|c|c|c|}
\hline Group & $\mathrm{N}$ & $\begin{array}{l}\text { Right } \\
\text { hemi- } \\
\text { sphere }^{a}\end{array}$ & $\begin{array}{c}\text { Left } \\
\text { hemi- } \\
\text { sphere }^{\text {a }}\end{array}$ & $\mathrm{apCO}_{2}$ \\
\hline Patients I & 28 & $\begin{array}{l}44.9(6.0) \\
P=0.006\end{array}$ & $\begin{array}{l}44.5(6.0) \\
P=0.007\end{array}$ & $\begin{array}{l}38.0 \\
P=1.13\end{array}$ \\
\hline Reference & 72 & $\begin{array}{l}48.4(5.4) \\
P=0.058\end{array}$ & $\begin{array}{l}47.9(5.4) \\
P=0.13\end{array}$ & $\begin{array}{l}38.8 \\
P<0.024\end{array}$ \\
\hline Patients II & 28 & $46.1 \quad(5.3)$ & $46.0(5.4)$ & 37.1 \\
\hline
\end{tabular}

a Standard deviation in parentheses.
The decrease was somewhat larger in the left occipital areas than in the same areas on the right side.

Figure 2 shows increases in regional CBF in the patient group from the time of diagnosis to follow-up. The flow increased in the majority of the areas measured. The largest increases were seen in the prefrontal areas bilaterally and in the temporooccipital areas, particularly in the left hemisphere.

\section{Covariation}

We did not find any significant correlation between the age of the patients and the flow increase during the follow-up period $(r=0.26)$. The covariation between the length of the follow-up period and the degree of mean flow normalization was also found to be nonsignificant $(r=0.03)$. We found, however, a statistically significant negative correlation $(r=-0.52$, $\mathrm{P}<0.005$ ) between the initial mean flow level and the degree of mean flow normalization during the followup period. Thus patients with an initially lower mean regional $\mathrm{CBF}$ level showed more marked normalization. Whether patients were exposed or not at the time of the first examination had no influence on the improvement in the follow-up regional CBF value. The only psychometric test which showed significant improvement in the follow-up examination was Benton's Revised Visual Retention Test (17). No significant correlation was, however, found between the improvement of the Benton error scores and the blood flow increase.

\section{Discussion}

We have previously reported reduced $\mathrm{CBF}$ in paint factory workers exposed long-term to organic solvents, especially in the prefrontal and frontotemporal areas

\section{Regional CBF differences}
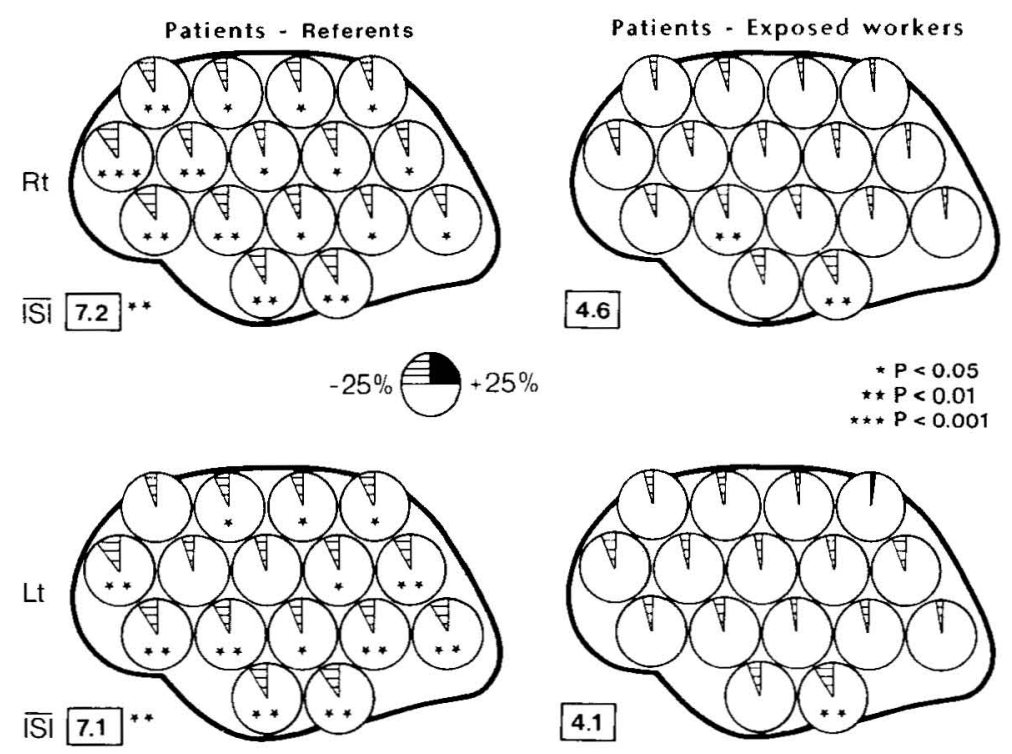

Figure 1. Mean (ISI) and regional cerebral blood flow (CBF) differences in the right (Rt) and left (Lt) hemispheres between the patients and referents and the patients and currently exposed paint factory workers. Lower regional flow in the patients is shown as striped clock symbols in the circles. A $90^{\circ}$ striped angle denotes $25 \%$ lower flow. Significances by the two-sample t-test. 
(16). In the present study of patients with a diagnosis of chronic toxic encephalopathy, based on neurasthenic symptoms and subnormal neuropsychological performance, the regional CBF reduction was larger and regionally more generalized. The largest flow reductions were, however, seen in prefrontal and frontotemporal areas also in this group. Thus, the flow reductions were more extensive in the present patient group and indicated more pronounced dysfunction.

Arlien-Søborg et al (14) reported a $19 \%$ decrease in the mean $\mathrm{CBF}$ level of nine house painters when they were compared with 11 unexposed referents; this decrease is a larger flow reduction than that recorded for the present group. The discrepancy is probably due to subject selection criteria and sample size differences. For example, our patients had normal CT results, while Arlien-Søborg et al included patients with abnormal CT findings. These patients may thus have been more organically affected than those included in the present study. Furthermore, we have found that there is a considerable variance of the CBF level of normal subjects at all ages, and thus, for reliable control data to be obtained, the reference group must be large (24).

Regionally, we found the largest flow decreases in frontal and frontotemporal areas. We have previously reported similar frontal regional $\mathrm{CBF}$ reductions in chronic alcohol abusers $(12,13)$.

The personality changes, the difficulties in concentration, and the lack of initiative displayed by our patients are symptoms also shown by patients with frontal lobe disorders, like frontal lobe dementia (11). Thus the symptoms displayed by the exposed patients agree well with what can be expected in frontal lobe disorders.

Growing experimental evidence suggests that longterm exposure to many different organic solvents results in changes in the nervous system which are based on structural breakdown and cellular alterations (18). Chronic neurotoxicity is believed to involve the oxidative metabolism of solvents to reactive intermediates in the neurons and glial cells, which then bind to vital intracellular macromolecules, proteins, ribonucleic acid (RNA) and deoxyribonucleic acid (DNA). This occurrence results in prolonged and progressive cellular dysfunction and eventual cell death (25). Such effects are likely to cause the regional CBF decreases seen in toxic encephalopathy.

We have no definite explanation for the frontal accentuation of the flow reduction in patients with toxic encephalopathy. Experimental evidence suggests, however, that certain organic solvents could induce irreversible astrogliotic alterations in some brain areas known to be sensitive also to chronic ethanol intake (26). Chronic ethanol abuse in man has been reported to result in histopathological glial cell changes (gliosis), especially in the frontal cerebral cortex, hippocampus, and central parts of the cerebellum (26). A higher vulnerability of the frontal cerebral cortex to such an
Increases of rCBF from initial measurement to follow-up
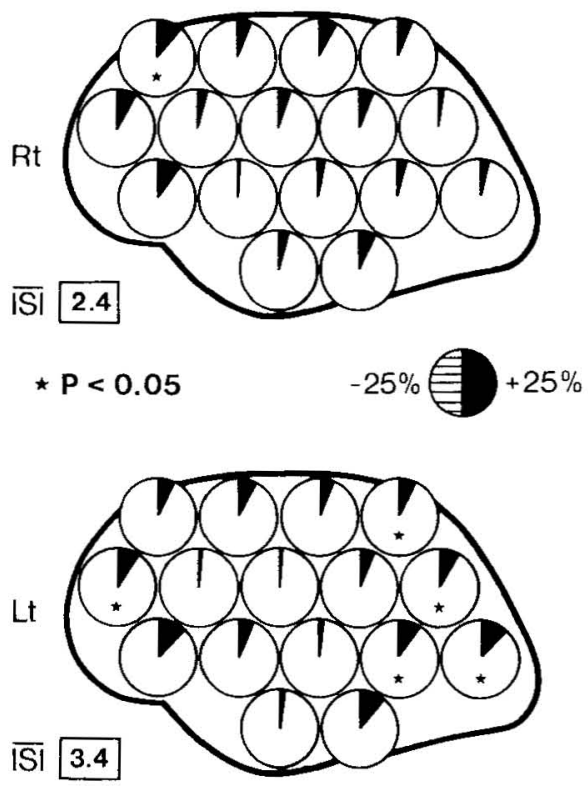

Figure 2. Increases of mean (ISI) and regional cerebral blood flow (rCBF) in the right (Rt) and left (Lt) hemispheres from the initial measurement to the follow-up in the patient group. Regional increases are shown as shadowed clock symbols in the circles. Shadowing of $180^{\circ}$ corresponds to a $25 \%$ flow increase. Significances by the paired-sample t-test.

influence might thus be the cause of the frontal accentuation of regional CBF pathology.

The significant negative correlation found between the initial mean flow level and the change at followup indicates that patients with a low initial mean flow level normalize their CBF to a greater extent than patients with a high initial level. It is not likely that this phenomenon is caused by regression towards the mean since a low CBF level was not used as a selection criteria for the group. The results are in agreement with our recent finding of a normalization of regional CBF in chronic alcohol abusers during abstinence (13). A subgroup of older alcoholics with a low mean flow level showed more marked normalization during seven weeks of abstinence than younger alcoholics with less reduced regional $\mathrm{CBF}$.

We had difficulties in establishing dose-response relationships in the present study, which illustrates the problems of assessing individual long-term exposure levels reliably. There is probably also a high degree of variation in individual susceptibility due to factors like the intensity, duration, and profile of exposure. Factors, like work load, protective measures, and previous health status may also vary and result in marked variability in the exposure-response relationships. This probability is further illustrated by the fact that some of our patients were less exposed than the fully active paint factory workers previously examined. 
The regional CBF findings agree well with the results of the electroencephalographic power-spectrum analysis of the present patient group (20), which showed an increase in total power that was more marked than the increase observed in the previously examined exposed workers (16). Some normalization was seen in the follow-up, but the power did not decrease to the level of the unexposed referents.

Previous follow-up studies have indicated that, once chronic toxic encephalopathy has developed, reversibility or further progression is not seen after exposure has been discontinued. Our regional CBF data indicate, however, some normalization of brain function. As has been observed in chronic alcoholics (13), normalization was seen primarily in patients with a low initial mean flow level, and this finding possibly indicates that patients with a high CBF level are less organically affected.

In conclusion, the regional CBF data confirm organic brain involvement in chronic toxic encephalopathy. The follow-up results suggest some improvement in brain function after the discontinuation of exposure, a finding which indicates that active rehabilitation for patients with chronic toxic encephalopathy may be meaningful.

\section{Acknowledgments}

The study was supported by grants from the Swedish Work Environment Fund (ASF 78-294, 82-1011) and the Swedish Medical Research Council (contract 4969). K Svensson, MSc, is thanked for his aid with the statistical analysis and Ms S Karlsson and Ms $\mathrm{H}$ Fernö are thanked for their assistance with the rCBF measurements and the preparation of the illustrations.

\section{References}

1. Axelson $\mathrm{O}$, Hane M, Hogstedt C. A case-referent study on neuropsychiatric disorders among workers exposed to solvents. Scand J Work Environ Health 1976;2:1420.

2. Elofsson S-A, Gamberale F, Hindmarsh $\mathrm{T}$, et al. Exposure to organic solvents: a cross-sectional epidemiologic investigation on occupationally exposed car and industrial spray painters with special reference to the nervous system. Scand J Work Environ Health 1980;6: 239-73.

3. Mikkelsen S. A cohort study of disability pension and death among painters with special regard to disabling presenile dementia as occupational disease. Scand J Soc Med 1980;(suppl 16):34-43.

4. Olesen J, Sabroe S. A case reference study on neuropsychiatric disorders among workers exposed to solvents in the Danish wood and furniture industry. Scand J Soc Med 1980;suppl 16:44-9.

5. Gregersen $P$, Angelsø $B$, Nielsen TE, Norgård B, Uldal C. Neurotoxic effects of organic solvents in exposed workers: an occupational, neurophysiological and neurological investigation. Am J Ind Med 1984;5:210-5.

6. Hane M, Axelson O, Blume J, Hogstedt C, Sundell L, Ydreborg B. Psychological function changes among housepainters. Scand J Work Environ Health 1977; 3:91-9.

7. Hänninen H. Psychological test methods: sensitivity to long term exposure at work. Neurobehav Toxicol 1979;1 (suppl 1):157-61.

8. Lindström K. Psychological performances of workers exposed to various solvents. Work Environ Health 1973;10:151-5.

9. Risberg J, Ali Z, Wilson EM, Wills EL, Halsey JH. RCBF by ${ }^{133}$ Xenon inhalation: preliminary evaluation of an initial slope index in patients with unstable flow compartments. Stroke $1975 ; 6: 142-8$.

10. Risberg J. Regional cerebral blood flow measurements by ${ }^{133} \mathrm{Xe}$-inhalation: methodology and applications in neuropsychology and psychiatry. Brain Lang 1980;9: 9-34.

11. Risberg J, Gustafson L. ${ }^{133}$ Xe cerebral blood flow in dementia and in neuropsychiatry research. In: Magistretti $P$, ed. Functional radionuclide imaging of the brain. New York, New York: Raven Press, 1983:15160.

12. Berglund M. Cerebral blood flow in chronic alcoholics. Alcohol Clin Exp Res 1981;5:295-303.

13. Berglund $\mathbf{M}$, Hagstadius $\mathbf{S}$, Risberg $\mathbf{J}$, Johanson $\mathbf{M}$, Bliding $\AA$, Mubrin $Z$. Normalization of regional cerebral blood flow in alcoholics during the first seven weeks of abstinence. Acta Psychiatr Scand 1987;75: 202-8.

14. Arlien-Søborg P, Henriksen L, Gade A, Gyldensted C, Paulsen OB. Cerebral blood flow in chronic toxic encephalopathy in house painters exposed to organic solvents. Acta Neurol Scand 1982;66:34-41.

15. Maximilian VA, Risberg J, Prohovnik I, Rehnström S, Hæger-Aronsen B. Regional cerebral blood flow and verbal memory after chronic exposure to organic solvents. Brain Cognition 1982;1:196-205.

16. Ørbæk P, Risberg J, Rosén I, et al. Effects of long-term exposure to solvents in the paint industry: a crosssectional epidemiologic study with clinical and laboratory methods. Scand J Work Environ Health 1985;11 (suppl 2): $1-28$.

17. Ørbæk P, Lindgren M. Prospective clinical and psychometric investigation of patients with chronic toxic encephalopathy induced by solvents. Scand J Work Environ Health $1988 ; 14: 37-44$.

18. WHO/Nordic Council of Ministers Working Group. Organic solvents and the central nervous system. Copenhagen: World Health Organization, 1985. (Environmental health 5.)

19. Ørbæk P, Lindgren M, Olivecrona $H$, Hæger-Aronsen B. Computed tomography and psychometric test performance in patients with solvent induced chronic toxic encephalopathy and healthy controls. $\mathrm{Br} \mathrm{J}$ Ind Med 1987;44:175-9.

20. Ørbæk P, Rosén I, Svensson K. Power spectrum analysis of EEG at diagnosis and follow-up of patients with solvent induced chronic toxic encephalopathy. $\mathrm{Br} \mathrm{J}$ Ind Med 1988;45:476-82.

21. Mallet BL, Veall N. Measurement of regional cerebral clearance rates in man using 133-Xenon inhalation and extracranial recording. Clin Sci 1965;29:179-88.

22. Obrist WD, Thompson HK, Wang HS, Wilkinson WE. Regional cerebral blood flow estimated by $133-$ Xenon inhalation. Stroke 1975;6:245-56.

23. Maximilian VA, Prohovnik I, Risberg J. Cerebral hemodynamic response to mental activation in normoand hypercapnia. Stroke 1980;11:342-7.

24. Hagstadius S, Risberg J. Regional cerebral blood flow characteristics and variations with age in resting normal 
subjects. Brain Cognition (in press).

25. Savolainen $\mathrm{H}$. Some aspects of the mechanisms by which industrial solvents produce neurotoxic effects. Chem Biol Interact $1977 ; 18: 1-10$.

26. Rosengren LE. Astroglial reactions to organic solvent toxicity [Academic thesis]. Göteborg (Sweden): Institute of Neurobiology, University of Göteborg, 1985.

Received for publication: 20 July 1987 